\title{
Enhancing Maternal Ability: Mediating for Pre-school Age Children's Cognitive Development
}

\author{
Leny Latifaha, Diah Yunitawati $^{\mathrm{b}}$, Yusi Dwi Nurcahyani ${ }^{\mathrm{c}}$, Suryati \\ Kumorowulan ${ }^{\text {d, a,b,c,d }}$ Magelang Unit of Health Research and Development \\ Centre, National Institute of Health Research and Development, Ministry of

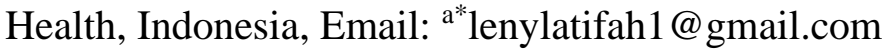

The multifactorial risks that accompany IDD (Iodine Deficiency Disorders) aggravate cognitive development deficits in children. The most important factors are poor cognitive stimulation and parenting. This study aimed to analyse the impact of parenting training on maternal skills to mediate cognitive development in children. The study was quasi-experimental pre-post with a control group design. A total of 78 mothers and their children, aged four to five years, from Purworejo participated in the research. Palpation to assess maternal goiter status and Mother-Child Picture-Talk Task (MCPTT) assessed the ability to perform cognitive mediation in children. The Smart Mother Class, a parenting skill intervention, was given for six months (16 meetings), each lasting 60-90 minutes. The risk of low family resources, both economic and caring resources, is indicated by the work and education of the fathers and mothers. Most mothers and fathers have elementary school education and below (60.3). The result show that three months after the intervention there was a significant effect at the positive level, and at six months, the intervention group showed a significant improvement $(\mathrm{p}<0.001)$. Parenting training in low parenting resource settings could improve maternal skills for mediating cognitive development in pre-school age children.

Key words: Cognitive Development, Maternal Mediation, Pre-school Age, Iodine Deficiency

\section{INTRODUCTION}

Children in IDD endemic areas have a higher risk of experiencing cognitive-developmental impairment. Iodine is a micronutrient essential in brain development (Qian et al., 2005; van den Briel et al., 2000). Iodine deficiency is not the only problem associated with intellectual 
deficit in the endemic IDD. The characteristics of IDD areas, usually in mountainous and rural areas, with limited infrastructure and access, are also associated with poor health and nutritional conditions (Kennedy, Nantel, \& Shetty, 2003). The multifactorial risks that accompany IDD aggravate the cognitive development deficits of children in IDD endemic areas, and the most critical factors are the lack of stimulation in children care in home environment (Huda et al., 1999; Taylor, 1993).

Developing countries still face an enormous problem of poverty and the risk of malnutrition, which leads to child development deficiency. Cognitive stimulation in IDD endemic areas needs to be enacted from an early age. Parenting is among the critical approaches to cognitive stimulation for children. Cognitive stimulation intervention studies with parenting ways have not explained sufficiently how parenting behaviour change is obtained or the determinants of behaviour that become targets for change toward enhancing the quality of care.

One of the psychological theories relevant to improving the quality of cognitive stimulation through parenting is Vygotsky's theory. Vygotsky explained that cognitive development takes place in two parts. First, when there is the interaction between humans, the second taking place when the individual is internalised (Kozulin, Gindis, Ageyev, \& Miller, 2003). The ability to mediate cognitive development allows mothers to organise the environment into children's learning resources. Children can then learn effectively and generate confidence in their learning abilities (Kim \& Mahoney, 2004).

The results of previous studies show that mothers with higher levels of education and family income interact more frequently with their children, they involve children with more outgoing activities, and provide more stimulation and teaching in the home environment (Baharudin \& Luster, 1998; Bradley \& Corwyn, 2002; Campbell \& Parcel, 2009; Dearing \& Taylor, 2007). Concerning cognitive development, an understanding of the role of specific parenting behaviour is still required to develop interventions, especially for children who are at risk of experiencing cognitive-developmental barriers and poor academic achievement, due to a less supportive environment and limited resources (Robinson, Burns, \& Davis, 2009). Based on these descriptions, this study aims to analyse the effects of parenting-based cognitive stimulation interventions on maternal parenting abilities. Based on these descriptions, this study aims to analyse the effects of parenting-based cognitive stimulation interventions on maternal parenting abilities, specifically in verbally mediating child cognitive development.

\section{METHODS}

\section{Research design}

This research is a quasi-experimental study, pre-post with a control group design. All mothers received $30 \mathrm{ppm}$ iodised salt and nutritional counselling with materials on the prevention and 
overcoming of IDD, anemia and malnutrition at the family level. Mothers in the intervention group attended a parenting-based cognitive stimulation training session for six months. This study was part of a parenting-based cognitive stimulation intervention study accompanied by controlled salt administration of $30 \mathrm{ppm}$ to improve child development (Latifah, Ismail, Gamayanti, \& Prabandari, 2013). This article focused on the use of Vygotsky's theory for the development of maternal cognitive abilities to mediate child cognitive development. Details of each level of maternal ability to mediate cognitive development in children was also further analysed and discussed.

A training module of caregiving for mothers in IDD endemic areas had been prepared and tested in the previous year (Latifah, 2011). Parenting training activities were called "a smart mother class". This training aimed to increase parenting skills in vulnerable families with the risk of poor parenting and limited resources, to help them develop parenting capacity through structured stages in parenting training sessions, which were expanded with interaction sheets to work upon with their children, at home.

The development goals to be achieved refer to Piaget's theory of cognitive development, which is the pre-operational stage. Piaget provides clear and operational traits and stages of cognitive development. The thoughts of Ki Hadjar Dewantara, especially the one concerning family as one of the centres of education, the principle of "among" or caring, and the mother as the first and foremost child educator, were embedded in the training materials. The material provided scaffolding skills, and elaborative speaking and its application in language stimulation and reasoning activities. The theoretical basis of the parental training class refers to Vygotsky's sociocultural theory, whereby the training aims to improve the ability of parents to facilitate cognitive development in their children.

\section{Research setting}

\section{Sample}

IDD endemic areas were chosen purposefully due to prior data as study sites (Kumorowulan, Nurcahyani, Slamet, \& Sugianto, 2012). Randomised cluster sampling was used to choose the sample. Random sampling was conducted with village clusters to determine which group received stimulation or non-stimulation. A total of three villages were selected as intervention areas and three villages as control areas. All children aged four to five years in the study site were registered, then randomly chosen as a sample along with their mothers.

The research was conducted in Pituruh Subdistrict, Purworejo Regency, on 78 mothers with children aged four to five years. The age of four to five years was chosen because cognitive and pre-academic skills at pre-school age were predictors of educational success and cognitive abilities at primary school age, even persisting until early and late adolescence. The inclusion criteria for mothers who participate in training include: (a) a healthy body condition, 
determined by a medical examination by a doctor, (b) the biological mother is the primary caregiver for the child, (c) the mother and child have resided in the study area for at least the last two years, (d) willingness to follow the research procedure, stated by the mother signing the informed consent. Exclusion criteria included suffering from chronic pain or physical disabilities.

\section{Measurement}

Personal data questionnaires were used to collect family characteristics, including data on the parent's job and education, obtained by interview. A doctor assessed maternal goiter enlargement by palpation. A psychologist assessed maternal intelligence by CFIT (Culture Fair Intelligent Test) scale 3 for adults. The CFIT was developed by Raymond Cattel, as a test that is value-free, culture-free, and universally understood. CFIT measures fluid intelligence, assessing analytical and reasoning abilities.

The maternal variable outcome is the maternal ability to mediate cognitive development in children (MCDC). Maternal ability to mediate cognitive development was assessed by the mother-child picture-talk task (MCPTT). The mother-child picture-talk task evaluates the role of the mother as a mediator of children's cognitive development through a series of verbal interaction tasks between mother and child. The tester gave a laminated sheet of paper with images on both sides to the mother. The tester wanted to see how the mothers talk about the images with the child, as they usually conversed with the children daily. One side had a landscape picture (which was the same in all pre-post tests). The second side had six images in a grid. The series of images presented at the pretest is different from the posttest. The tester coded every word of the mother, with the following code: level 0 , negative (criticising, not supporting the task); level 1, directing (commanding, giving a name); level 2, asks, answering children's questions, explaining further details (not just giving names); level 3 (relates to children's behaviour/experiences), encourages children to ask questions or expand on stories, asks children to explain something by giving open-ended questions; gives positive comments. The frequency of each code is recorded. The test takes about four to five minutes. Children's speech is coded by category: not related to tasks, repeating the mother's words, answering, giving names, asking questions, and describing details (Aboud and Akhter, 2011; Aboud, 2007). This study used MCPTT, extended version. Scoring and reporting were carried out at each level. Before the research, the perception of the three raters involved was equalised.

\section{Data analysis}

Descriptive analysis was carried out to see a description of the characteristics of the subject. To compare intervention and control group results, t-test and ANOVA tests were used. 
International Journal of Innovation, Creativity and Change. www.ijicc.net

Volume 15, Issue 8, 2021

\section{Ethical consideration}

The research received a review from the scientific commission and ethical approval from the ethics committee of the Health Research and Development Agency of the Indonesian Ministry of Health.

\section{RESULTS}

Most mothers work as housewives (68.4\%), and the fathers work as agricultural labourers (53.9\%). Most mothers (60.5\%) and fathers (60.5\%) have primary school education and below. This data indicates the risk of a lack of family resources, both economic and care resources.

Table 1. Demographic characteristics of the family

Variable n (percentage)

Mother's Education

- Never went to school

$1(1.3 \%)$

- Not completed primary school

$16(21.1 \%)$

- Graduated from elementary school

$30(39.5 \%)$

- Graduated from junior high school

$19(25 \%)$

- Graduated from high school

$10(13.6 \%)$

Father's education

- Never went to school

$1(1.3 \%)$

- Not completed primary school

- Graduated from elementary school

$32(42.1 \%)$

- Graduated from junior high school

$20(26.3 \%)$

- Graduated from high school

$10(13.6 \%)$

Mother's work

- Housewife

$52(68.4 \%)$

- Private employee

$2(2.6 \%)$

- Entrepreneur / Trader / Service

$4(5.3 \%)$

- Farm owner

$6(7.9 \%)$

- Farmworker

$12(15.8 \%)$

Father's work

- Does not work

- PNS / TNI / POLRI

- Private employee

- Entrepreneur / Trader / Service

- Farm owner

- Farm worker 
International Journal of Innovation, Creativity and Change. www.ijicc.net

Volume 15, Issue 8, 2021

- Other

$1(1.3 \%)$

Based on goiter enlargement criteria, as many as 15.4 percent of mothers have goiter enlargement. Based on this, the area was defined as mildly endemic. Besides the low level of education and parental work, the low level of care resources was exacerbated by the low level of maternal intelligence (mean $66.4 \pm 14.5$ ).

Table 2. Characteristics of maternal intelligence and goitre status

\begin{tabular}{lc}
\hline \multicolumn{1}{c}{ Variable } & n (percentage) \\
\hline Mother's goiter status & \\
$\bullet \quad$ Enlargement & $12(15.8 \%)$ \\
$\bullet \quad$ Normal & $64(84.2 \%)$ \\
\hline Mother's IQ & \\
$\bullet$ Normal & $44(57.1 \%)$ \\
$\bullet$ Hampered & $33(42.8 \%)$ \\
\hline
\end{tabular}

The assumption test on the maternal skills to mediate children's cognitive shows that the distribution of data on the subject is normal. The homogeneity test with the Box's M test and Levene showed that both overall and at each time level, the data on maternal skills scores in the intervention and control groups were homogeneous ( $p<0.05)$. The assumption of sphericity is accepted.

Table 3. Results of mixed design ANOVA analysis on children's cognitive mediation

\begin{tabular}{lccccc}
\hline \multicolumn{1}{c}{ Variables and Sources } & df & SS & MS & F & P \\
\hline Time & 2 & 804.38 & 402.19 & 6.16 & 0.003 \\
Group * time & 2 & 3391.96 & 1695.98 & 25.98 & 0.000 \\
Error & 148 & 9662.95 & 62.29 & & \\
\hline Group & 1 & 925.47 & 925.47 & 4.64 & 0.034 \\
Error & 74 & 14746.19 & 199.27 & & \\
\hline
\end{tabular}

The main effect of time shows that the mother's child cognitive mediation score (MCM) showed a significant change over time $(\mathrm{F}=6.16 ; \mathrm{p}=0.003)$. The interaction effect of time and treatment also showed a significant difference $(F=25.98 ; p=0.000)$. Thus, changes in MCM scores over time differed significantly between the control group and the intervention group. The main effect for the groups showed that the increase in the ability of MCM in the intervention group over time was significantly higher than the control group. Parenting-based cognitive stimulation intervention significantly increased $\mathrm{MCM}(\mathrm{F}=4.64 ; \mathrm{p}=0.034)$.

The intervention group showed a pattern of increasing the ability of mothers to mediate children's cognitive better than the control group. The intervention factor contributed to an increase in the cognitive mediation ability of children in the intervention group by 43.5 percent, while the increase in the control group was 12 percent. 
The results of the time difference test in the same group showed that the intervention group experienced a significant increase, both at the third month and the sixth-month measurement. The control group did not show any significant improvement in the third month of assessment. Even at the sixth month, there was a significant decrease in the value of the mother's skills in performing cognitive mediation of children, compared to the initial time.

Table 4. The skills development of mothers in conducting cognitive mediation of children before and after the intervention

\begin{tabular}{lccc}
\hline \multicolumn{1}{c}{ Variable } & $\begin{array}{c}\text { Ex. Intervention } \\
\overline{\mathbf{x}}(\mathbf{S D})\end{array}$ & $\begin{array}{c}\text { Ex. Control } \\
\overline{\mathbf{x}}(\mathbf{S D})\end{array}$ & pa \\
\hline MCM 0 months & $34.85(8,55)^{1}$ & $38.54(10.79)^{1}$ & 0.101 \\
MCM 3 months & $41.0(9.87)^{2}$ & $39.80(10.39)^{1}$ & 0.608 \\
MCM 6 months & $48,24(12,89)^{3}$ & $33.63(13.66)^{2}$ & $0,000 *$ \\
\hline Pb & 0.000 & 0.009 & \\
Partial $\eta 2$ & 0.435 & 0.120 & \\
\hline
\end{tabular}

$\overline{1,2,3}$ in the same group, values with different numbers indicate a significant difference between times $(p<0.05)$ based on the value of the paired sample t-test.

$\mathrm{pa}=$ significance value of the difference between groups based on the value of the independent sample t-test

$\mathrm{pb}=$ significance value of simple effects multivariate of time at each treatment level Partial $\eta 2$ by Willk's Lambda

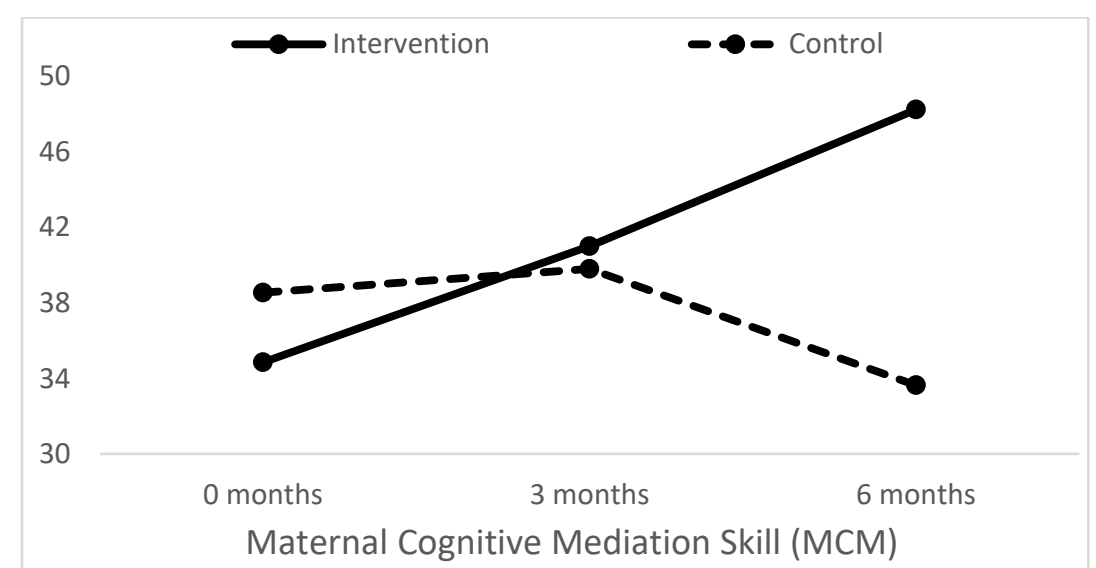

Figure 4. Graph of the maternal skill in conducting cognitive mediation of children based on the level over time.

In the different tests between treatment groups, measurements carried out three months after the intervention did not show a significant effect of the intervention on the mother's ability to mediate cognitive mediation of children in general. At six months, the intervention group showed a very significant improvement compared to the control group ( $p<0.001)$. 
International Journal of Innovation, Creativity and Change. www.ijicc.net

Volume 15, Issue 8, 2021

Furthermore, further analysis of changes in maternal ability in each level of MCM was carried out (table 5).

Table 5. Maternal skills in mediating cognitive development of children based on the level overtime

\begin{tabular}{lcccc}
\hline \multicolumn{1}{c}{ Variable } & $\begin{array}{c}\text { Ex. Intervention } \\
\overline{\mathbf{x}}(\mathbf{S D})\end{array}$ & $\begin{array}{c}\text { Ex. Control } \\
\overline{\mathbf{x}}(\mathbf{S D})\end{array}$ & $\mathbf{t}$ & $\mathbf{p}$ \\
\hline MCM level 0 months 0 & $0.51(0.98)^{1}$ & $1.29(2.15)^{1}$ & $-2,069$ & $0.042 *$ \\
MCM level 1 month 0 & $11.49(6.91)^{1}$ & $12.77(5.69)^{1}$ & $-0,875$ & 0.385 \\
MCM level 2 months 0 & $17.32(8.15)^{1}$ & $16.29(5,52)^{1}$ & 0.646 & 0.520 \\
MCM level 3 months 0 & $5.54(6.61)^{1}$ & $6.97(6.18)^{1}$ & $-0,972$ & 0.334 \\
\hline MCM level 0 months 3 & $0.17(0.49)^{2}$ & $0.94(1.55)^{1}$ & $-3,014$ & $0.004 *$ \\
MCM level 1 month 3 & $8.8(5.15)^{2}$ & $10.2(7,27)^{1}$ & $-1,136$ & 0.260 \\
MCM level 2 months 3 & $18.22(7.83)^{1}$ & $20.49(10.79)^{2}$ & $-1,300$ & 0.198 \\
MCM level 3 months 3 & $13,98(9,55)^{2}$ & $9.11(8.99)^{1}$ & 2,274 & $0.026 *$ \\
\hline MCM level 0 months 6 & $0.93(1.71)^{1}$ & $1.4(1.72)^{1}$ & $-1,200$ & 0.234 \\
MCM level 1 month 6 & $10.63(6.77)^{1}$ & $9,291(5,77)^{2}$ & 0.925 & 0.358 \\
MCM level 2 months 6 & $22.51(10,19)^{3}$ & $17.14(8,11)^{1}$ & 2,510 & $0.014 *$ \\
MCM level 3 months 6 & $15.1(12,31)^{2}$ & $7.2(5,58)^{1}$ & 3,498 & $0.001 *$ \\
\hline
\end{tabular}

$1,2,3$ In the same group, values with different numbers indicate a significant difference between times $(\mathrm{p}<0.05)$ based on the value of the paired sample t-test.

$\mathrm{p}=$ significance value of the difference between groups based on the value of the independent sample t-test

* significant at $\mathrm{p}$ value $<0.05$

Maternal ability to mediate cognitive development in children consists of four levels, starting from level 0, not supporting the task or negative verbal. Level 1 directs verbal behaviour, including ordering, giving names, referred to, as the level of verbal directing. Level 2 is the descriptive verbal level, it includes verbal behaviour of asking questions, answering children's questions, explaining further details (not just giving names). Level 3 is elaborative verbal, it includes connecting the image with children's behaviour/experiences, encouraging children to ask questions or expand on stories, asking children to explain something by giving open-ended questions, and giving positive comments. The intervention aims to improve the ability of mothers to do MCM verbally at a higher level. 
nternational Journal of Innovation, Creativity and Change. www.ijicc.net

Volume 15, Issue 8, 2021

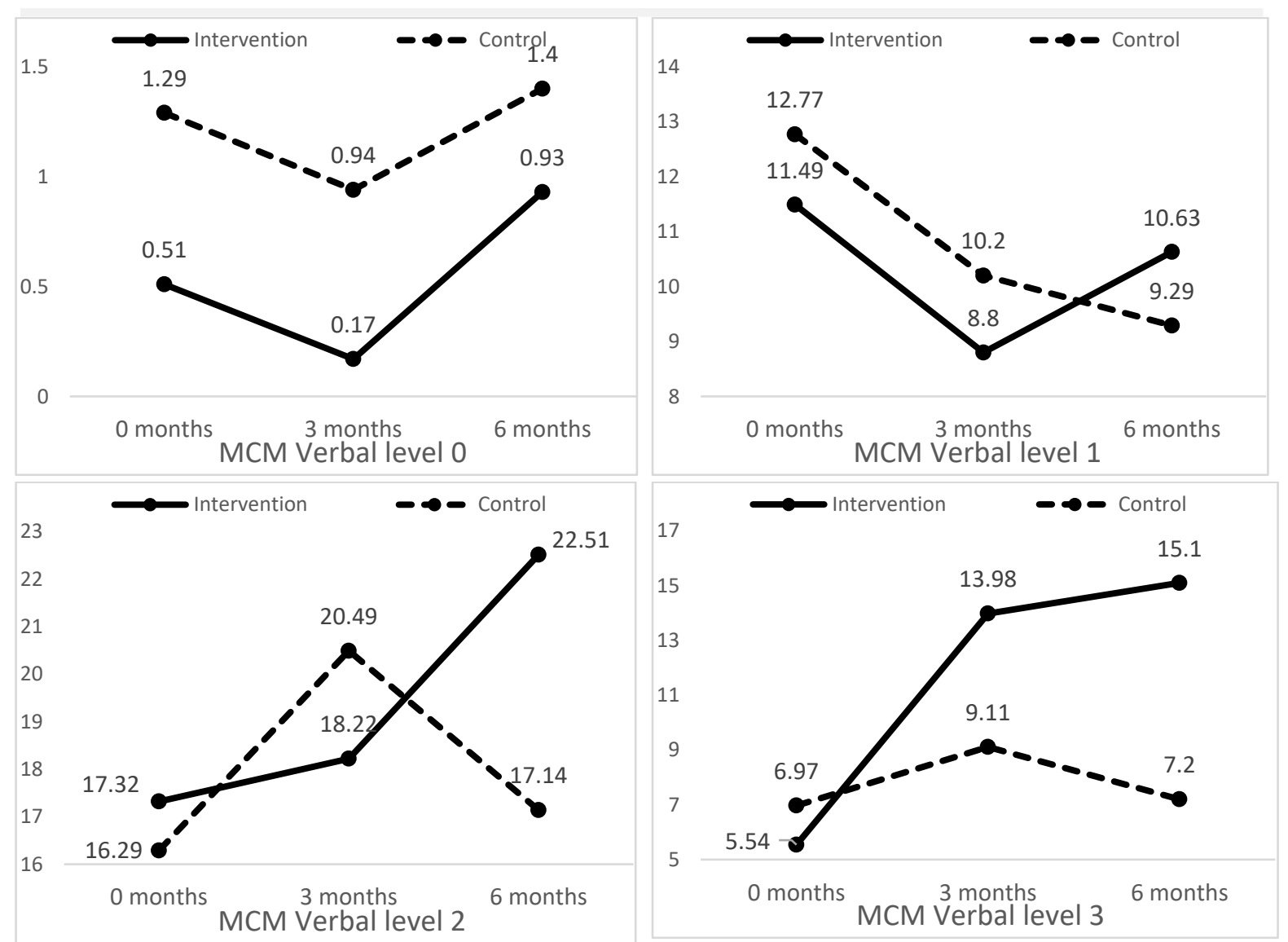

Figure 1. Graph of the maternal skill in mediating cognitive development in children for each maternal verbal level over time.

The description of the mother's ability on the MCM indicator at levels 0 to 3 was similar between the intervention and control groups at the beginning of the study. The frequency of MCM in the two groups was the lowest at the negative verbal level, still quite low at the elaborative level, followed by the directing verbal level, and most MCM was found at the descriptive level. The intervention group at the start of the measurement had a negative MCM score that was significantly lower than the control group.

In the three-month measurement, although in total there was no difference, which meant that the quantity of maternal MCM was still the same, but it was seen that the profiles of maternal MCM were different in the two groups. The elaborative level MCM ability of mothers in the intervention group was significantly higher than the control group in the third month. Measurements over time showed that the intervention succeeded in improving the quality of maternal MCM in the intervention group, noticed even since the third month. In the third month, there was a significant decrease in MCM negative, as well as a significant increase in MCM directing level and elaborative level. At the sixth month of measurement, there was a significant increase at the descriptive level and the elaborative level. 
In the control group, a significant increase occurred at the descriptive verbal level at the third month, while at the sixth month, in addition to a significant decrease in the total maternal ability to mediate cognitive development scores, there was a significant decrease in the directing level of MCM. There was no significant change in the elaborative level MCM of mothers in the control group, both at the third and sixth months.

\section{DISCUSSION}

Preliminary research in the Pituruh sub-district in 2011 showed the risk of IDD endemicity, born with cretinism, low consumption of iodised salt $(57 \%$ consumed salt <30ppm, $30 \%$ of which was salt that did not contain iodine). Kumorowulan's research (Kumorowulan et al., 2012) on 300 WUS in Pituruh also concluded that the condition of the area was mildly endemic, with 70 percent of women having EIU levels $<100$. Research in the same area also shows a low risk of cognitive abilities in pre-school children and a low risk of quality care that stimulates children's cognitive development (Latifah, 2012). Based on these preliminary data, a cognitive intervention model was developed with controlled administration of iodised salt (30ppm) to children in the Pituruh sub-district.

This is in line with studies of various studies showing that the spectrum of IDD in iodinedeficient populations includes the developmental period from fetus to old age (Hetzel, 2000). Research in Baihuyao China, showed 72 percent of adults in IDD endemic areas (born during severe IDD) have an IQ test score below 70. This indicates a moderate to severe deficit in intellectual capacity. Lack of intellectual capacity in adults also influences the increased risk of quality of care and the inability of parents to provide adequate cognitive stimulation for children (Boyages, 1993). Lack of support for care resources, including maternal parenting skills, increased the risk of children's cognitive development, indicated by the high prevalence of children's cognitive problems (Latifah, Kusrini, \& Kumorowulan, 2016).

This study shows that the risk of multi-factor obstacles to child development in endemic areas of IDD is quite large, especially in regard to socio-economic conditions and care resources. Strengthening family resources by increasing parenting skills is needed.

Quality of care is reflected through indicators of maternal ability to mediate cognitive development as measured by the task of mother-child picture talking task (MCPTT). Data analysis was used to compare intervention and control groups on the indicators of maternal cognitive mediation quality. Results of the analysis showed the two groups had the same initial condition of the ability to mediate cognitive development in children. This study, among others, uses Vygotsky's theory in developing parenting stimulation material, assessed with indicators of maternal skills in verbally mediating children's cognitive mediation. 
The intervention group did not show a significant difference in the total score of maternal ability to mediate cognitive development (mother-child picture talking task) after three months of intervention. Further analysis on aspects of the two positive indicators revealed that the intervention group showed improvement.

On the indicator of the ability to mediate cognitive development, mothers in the experimental group showed a very significant increase compared to the control group at level 3, namely the ability to speak elaborately, which is characterised by the use of richer language in interacting with children. Parent-child interaction, specifically parent-child conversation, is a critical instrument in children's developmental processes and outcomes (Fivush, Haden, \& Reese, 2006). Elaborative speaking is characterised by 1) the use of open question sentences, which allow children to answer broadly, 2) the ability to connect, the basic technique of which is when talking to children, the mother talks about what is happening now and connects with other things similar to what the child already knows.

Review research from Bradley et al. (Bradley et al., 1993) showed that the quality of the parenting environment is a mediator for the intellectual capacity of parents and children's cognitive abilities. The quality of environmental care becomes a more powerful mediator when the child is three years old than when the child is one year old. The results showed parents could make changes to parenting behaviour that improve children's development outcomes, including cognitive development (Bakermans-Kranenburg, van IJzendoorn, \& Bradley, 2005), parenting skills enhanced through training and interventions based on improving parenting skills (Guthrie, Gaziano, \& Gaziano, 2008; Smith, 2010). Cognitive interventions in early childhood are more successful when done at home and within maternal parenting framework interactions, involving activities and exploration of daily activities. Tudge and Douchet conducted a study on black and white families in America and found daily activities can be a source of stimulation in interactions (Tudge \& Doucet, 2004).

Meta-analysis of parenting stimulation interventions implemented in low and middle-income countries shows that these interventions are suitable for improving the caregiver environment at home, improving the quality of interactions between mothers and children, and for increasing mothers' knowledge of child development (Jeong, Pitchik, \& Yousafzai, 2018). The intervention will give positive results if it fulfills several intervention characteristics, including being carried out in a small group and given by professionals in their fields (Baudry, Tarabulsy, Atkinson, Pearson, \& St-Pierre, 2017).

This study shows that parenting-based cognitive stimulation interventions for six months with 16 meetings can improve the quality of care. Several things support the success of the intervention. Robinson (Robinson et al., 2009) states that concerning children's cognitive development, an understanding of the role of specific parenting behaviours is still needed to develop interventions, especially for children who are at risk of experiencing cognitive- 
developmental obstacles and poor academic, due to a less supportive environment. The mothers in this study had low educational backgrounds, cognitive abilities, and socio-economic levels.

\section{CONCLUSION}

Mothers who receive parenting-based cognitive stimulation training can improve cognitive development mediation skills in children, specifically descriptive and elaborative speaking skills. Scaffolding and elaborative speech principles were utilised in maternal stimulation activities. This research was conducted in maternal limited resources both in economic and care. The impact was significant at three months and more compelling at the six months intervention. The result raises awareness on the importance of parenting education, specifically in parents with the described vulnerable condition.

\section{ACKNOWLEDGMENT}

Researchers would like to express gratitude to Prof. Frances Aboud, which was very helpful in the adaptation process of Mother Child Picture Talk Task in an Indonesian context, especially in Javanese culture. We also thank to Purworejo District Health Officers, Head of Puskesmas Pituruh II, midwives and cadres. Our high appreciation also for the mothers and children who were involved in this research, for their time and participation. 
International Journal of Innovation, Creativity and Change. www.ijicc.net

Volume 15, Issue 8, 2021

\section{REFERENCES}

Angeles-Agdeppa, I., Schultink, W., Sastroamidjojo, S., Gross, R., \& Karyadi, D. (1997). Weekly micronutrient supplementation to build iron stores in female Indonesian adolescents. The American Journal of Clinical Nutrition, 66(1), 177-183. https://doi.org/10.1093/ajen/66.1.177

Baharudin, R., \& Luster, T. (1998). Factors Related to the Quality of the Home Environment and Children's Achievement. Journal of Family Issues, 19(4), 375-403. https://doi.org/10.1177/019251398019004002

Bakermans-Kranenburg, M. J., van IJzendoorn, M. H., \& Bradley, R. H. (2005). Those Who Have, Receive: The Matthew Effect in Early Childhood Intervention in the Home Environment. Review of Educational Research, 75(1), 1-26. https://doi.org/10.3102/00346543075001001

Baudry, C., Tarabulsy, G. M., Atkinson, L., Pearson, J., \& St-Pierre, A. (2017). Intervention with Adolescent Mother-Child Dyads and Cognitive Development in Early Childhood: a Meta-Analysis. Prevention Science : The Official Journal of the Society for Prevention Research, 18(1), 116-130. https://doi.org/10.1007/s11121-016-0731-7

Boyages, S. (1993). The Damaged Brain of Iodine Deficiency: Evidence for a Continuum of Effect on the Population at Risk. In J. Stanbury (Ed.), The Damaged Brain of Iodine Deficiency. Pennsylvania: The Franklin Institute.

Bradley, R. H., \& Corwyn, R. F. (2002). Socioeconomic Status and Child Development. Annual Review of Psychology, 53(1), 371-399. https://doi.org/10.1146/annurev.psych.53.100901.135233

Bradley, R. H., Whiteside, L., Caldwell, B. M., Casey, P. H., Kelleher, K., Pope, S., .. Cross, D. (1993). Maternal IQ, the Home Environment, and Child IQ in Low Birthweight, Premature Children. International Journal of Behavioural Development, 16(1), 61-74. https://doi.org/10.1177/016502549301600104

Campbell, L. A., \& Parcel, T. L. (2009). Children's Home Environments in Great Britain and the United States. Journal of Family Issues, 31(5), 559-584. https://doi.org/10.1177/0192513X09350441

Dearing, E., \& Taylor, B. A. (2007). Home improvements: Within-family associations between income and the quality of children's home environments. Journal of Applied Developmental Psychology, 28(5), 427-444. https://doi.org/https://doi.org/10.1016/j.appdev.2007.06.008

Fivush, R., Haden, C. A., \& Reese, E. (2006). Elabourating on elabourations: role of maternal reminiscing style in cognitive and socioemotional development. Child Development, 77(6), 1568-1588. https://doi.org/10.1111/j.1467-8624.2006.00960.x

Grantham-McGregor, S. M., Fernald, L. C., \& Sethuraman, K. (1999). Effects of Health and Nutrition on Cognitive and Behavioural Development in Children in the First Three Years of Life: Part 2: Infections and Micronutrient Deficiencies: Iodine, Iron, and Zinc. Food and Nutrition Bulletin. SAGE Publications. 
International Journal of Innovation, Creativity and Change. www.ijicc.net

Volume 15, Issue 8, 2021

Guthrie, K. F., Gaziano, C., \& Gaziano, E. P. (2008). Toward Better Beginnings: Enhancing Healthy Child Development and Parent - Child Relationships in a High-Risk Population. Home Health Care Management \& Practice, 21(2), 99-108. https://doi.org/10.1177/1084822308322650

Hetzel, B. S. (2000). Iodine and neuropsychological development. The Journal of Nutrition, 130(2S Suppl), 493S-495S. https://doi.org/10.1093/jn/130.2.493S

Huda, S. N., Grantham-McGregor, S. M., Rahman, K. M., \& Tomkins, A. (1999). Biochemical Hypothyroidism Secondary to Iodine Deficiency Is Associated with Poor School Achievement and Cognition in Bangladeshi Children. The Journal of Nutrition, 129(5), 980-987. https://doi.org/10.1093/jn/129.5.980

Jeong, J., Pitchik, H. O., \& Yousafzai, A. K. (2018). Stimulation Interventions and Parenting in Low- and Middle-Income Countries: A Meta-analysis. Pediatrics, 141(4). https://doi.org/10.1542/peds.2017-3510

Kennedy, G., Nantel, G., \& Shetty, P. (2003). The scourge of "hidden hunger": global dimensions of micronutrient deficiencies. Food, Nutrition and Agriculture (FAO)Alimentation, Nutrition et Agriculture (FAO)Alimentacion, Nutricion $y$ Agricultura (FAO).

Kim, J.-M., \& Mahoney, G. (2004). The Effects of Mother's Style of Interaction on Children's Engagement: Implications for Using Responsive Interventions with Parents. Topics in Early Childhood Special Education - TOP EARLY CHILD SPEC EDUC, 24, 31-38. https://doi.org/10.1177/02711214040240010301

Kozulin, A., Gindis, B., Ageyev, V., \& Miller, B. (2003). Vygotsky's Educational Theory in Cultural Context. In Learning in Doing: Social, Cognitive and Computational Perspectives. https://doi.org/DOI: 10.1017/CBO9780511840975

Kumorowulan, S., Nurcahyani, D., Slamet, A., \& Sugianto. (2012). Overview of Urine Iodine and TSH Excretion in WUS in iodine deficiency endemic areas. Poster AOTA International Seminar. Denpasar: AOTA.

Latifah, L. (2012). Parenting-Based Cognitive Stimulation Perception and Parctice towards Children in Iodine Deficiency Endemic Area. Media Gizi Mikro Indonesia, 4(1). Retrieved from http://ejournal.litbang.kemkes.go.id/index.php/mgmi/article/view/9219

Latifah, L., Ismail, D., Gamayanti, I. L., \& Prabandari, Y. S. (2013). Impact of Cognitive Stimulation and Iodised Salt for 3 Months on the Iodine Status, HOME Quality of Care and Cognitive Development in Under Five Cognitive Development in Iodine Deficiency Endemic Area. Indonesian Journal of Micronutrition, 5(1). https://doi.org/10.22435/mgmi.v5i1.3715.

Latifah, L., Kusrini, I., \& Kumorowulan, S. (2016). Maternal Factor Related to Pre-School Children Cognitive Ability in Iodine Deficiency Endemic Area. Jurnal Kesehatan Reproduksi, 7(3). Retrieved from http://ejournal.litbang.kemkes.go.id/index.php/kespro/article/view/5584/4936

Qian, M., Wang, D., Watkins, W. E., Gebski, V., Yan, Y. Q., Li, M., \& Chen, Z. P. (2005). The effects of iodine on intelligence in children: a meta-analysis of studies conducted in 
China. Asia Pacific Journal of Clinical Nutrition, 14(1), 32-42.

Robinson, J. B., Burns, B. M., \& Davis, D. W. (2009). Maternal scaffolding and attention regulation in children living in poverty. Journal of Applied Developmental Psychology, 30(2), 82-91. https://doi.org/https://doi.org/10.1016/j.appdev.2008.10.013

Smith, M. (2010). Good parenting: Making a difference. Early Human Development, 86(11), 689-693. https://doi.org/https://doi.org/10.1016/j.earlhumdev.2010.08.011

Taylor, C. (1993). Iodine Deficiency: What do we know and where do we go? In J. Stanbury (Ed.), The Damaged Brain of Iodine Deficiency. Pennsylvania: The Franklin Institute.

Tudge, J. R. H., \& Doucet, F. (2004). Early mathematical experiences: observing young Black and White children's everyday activities. Early Childhood Research Quarterly, 19(1), 21-39. https://doi.org/https://doi.org/10.1016/j.ecresq.2004.01.007

van den Briel, T., West, C. E., Bleichrodt, N., van de Vijver, F. J., Ategbo, E. A., \& Hautvast, J. G. (2000). Improved iodine status is associated with improved mental performance of schoolchildren in Benin. The American Journal of Clinical Nutrition, 72(5), 1179-1185. https://doi.org/10.1093/ajen/72.5.1179 